\title{
EXTERNAL INFORMATION AND MONETARY POLICY TRANSMISSION IN NEW EU MEMBER STATES: RESULTS FROM FAVAR MODELS
}

\author{
Zlatina Balabanova and Ralf BrügGemanN \\ University of Konstanz
}

We investigate the effects of monetary policy shocks in the new European Union (EU) member states the Czech Republic, Hungary, Poland, and Slovakia. In contrast to existing studies, we explicitly account for external developments in European Monetary Union (EMU) countries and in other acceding countries. We do so by using factor-augmented vector autoregressive models that employ information from nonstationary factor time series. One set of VAR models includes factors obtained from a large cross section of time series from EMU countries, whereas another set includes factors obtained from other acceding countries. We find that including EMU factors does change impulse response patterns in some but not all acceding countries. In contrast, including factors from other acceding countries leads to substantial changes in impulse responses and to economically more plausible results. Overall, our analysis highlights that taking external economic developments properly into account is crucial for the analysis of monetary policy in the new EU member states.

Keywords: Factor-Augmented VARs, Impulse-Response analysis, Monetary Policy Shocks, Central and Eastern European Countries, European Monetary Union

\section{INTRODUCTION}

On May 1, 2004, eight Central and Eastern European (CEE) countries entered the European Union (EU), among them the three largest CEE economies, the Czech Republic, Hungary, and Poland. EU membership may be seen as the first step toward European economic and monetary integration of accession countries. In fact, many of the new member states have plans to become members of the European Monetary Union (EMU) and to adopt the Euro as a common currency in the future. Moreover, some of the new acceding countries (Slovenia, Slovakia, Estonia, Latvia, Lithuania) have already adopted the Euro.

We thank the associate editor and two anonymous referees for helpful suggestions. We also thank seminar participants at the 11th IWH-CIREQ Macroeconometric Workshop, the Freie Universität Berlin research seminar, and the ESEM 2012 for useful comments on earlier versions of this paper. Research assistance by Robin Braun and financial support by the Deutsche Forschungsgemeinschaft, Project BR 2941/1-1, is gratefully acknowledged. Address correspondence to: Ralf Brüggemann, Department of Economics, University of Konstanz, Box 129, 78457 Konstanz, Germany; email: ralf.brueggemann@uni-konstanz.de. 
Economists argue that successful EMU membership requires the countries of the monetary union to be sufficiently similar, as otherwise common monetary policy may be difficult to implement [see, e.g., Dornbusch et al. (1998)]. Against this background, one aspect of economic integration that has received some attention in the literature is related to differences in monetary transmission mechanisms. Understanding how monetary transmission differs among (potential) EMU members is particularly relevant in the context of currency unions. Empirically, the effects of monetary policy shocks are usually investigated within small identified vector autoregression (VAR) models using techniques of innovation accounting such as impulse-response analysis. For instance, a number of studies focus on possible heterogeneity in the transmission mechanism in economies that formed the EMU in 1999 [see, e.g., Mihov (2001), Mojon and Peersman (2001), Peersman and Smets (2001), Ciccarelli and Rebucci (2002), Angeloni et al. (2003), and Ehrmann et al. (2003)]. Similarly, some attempts have been made to characterize and compare the monetary transmission mechanisms in individual EU acceding countries. Examples of studies on acceding countries include the work of Ganev et al. (2002), Coricelli et al. (2006), Elbourne and de Haan (2006), Anzuini and Levy (2007), and Gavin and Kemme (2009). The reported results for the individual countries are often ambiguous and sometimes the authors do not find evidence for a sensible monetary transmission mechanism. For instance, in addition to positive price responses to contractionary monetary policy shocks (the so-called "pricepuzzle"), the papers also report counterintuitive positive output responses for some of the countries. Thus, only a few robust conclusions emerge from the mentioned studies.

We argue that some of the counterintuitive results for the acceding countries found in the literature are due to mis-specification of the small VARs, as some important (external) variables are likely to be missing from the information set. The point of missing variables in the VAR is particularly relevant in the case of EU accession countries, because the work for those countries typically uses very small VAR systems, often including not more than four variables. This is because available time series are still relatively short and is in contrast to studies for the United States or other European countries. Using larger VARs is prohibitive, as the degrees of freedom in these models are quickly exhausted. ${ }^{1}$ Moreover, there are close trade links among the acceding countries themselves and between acceding countries and other EMU countries. For 2003, Bussière et al. (2005) report the percentage of trade (imports and exports) in CEE economies with Euro area countries. In the four countries of our empirical analysis, these trade shares range from $53.4 \%$ in Slovakia to $57.6 \%$ in Poland, 58.9\% in the Czech Republic, and $59.5 \%$ in Hungary. In other words, in each country more than half of the trading activities take place with EMU countries. Moreover, the share of trade in these countries with other new EU member states is also substantial. For 2003, Bussière et al. (2005) report corresponding shares that range from $7.3 \%$ in Hungary to $10.2 \%$ in Poland, $14.3 \%$ in the Czech Republic, and $24.8 \%$ in Slovakia. This suggests a prominent role for additional external variables in the VARs. 
Therefore, in this paper we explore to what extent accounting for external economic developments in the EMU and in other acceding countries changes the results from structural VAR models and the conclusion about the effects of monetary policy shocks. We do so by augmenting standard VAR models with factor time series that summarize parsimoniously the information from a large cross section of time series from EMU or acceding countries, as will be explained. This approach differs markedly from including just a few exogenous variables.

To summarize the external economic developments, we first condense the information contained in a large cross section of time series into a few factor time series using the techniques suggested by, e.g., Stock and Watson (2002b) and Bai and $\mathrm{Ng}$ (2004). To facilitate the interpretation of the factors, we relate them to the underlying time series by regressing the stationary factors on the individual variables. We then include the factor time series in the VARs of the acceding countries in two different ways. In a first variation, we adapt the factor-augmented VAR (FAVAR) approach of Bernanke et al. (2005) and augment the VARs with factor time series [see also Favero et al. (2005) for a related study]. Because some of the time series in the VARs are likely to be driven by stochastic trends and are also possibly cointegrated, we prefer to use VARs for the levels of the variables. This preserves all potential cointegration relationships. Correspondingly, we include the nonstationary factor time series obtained from the approach by Bai and $\mathrm{Ng}$ (2004). In the second variation, we include the nonstationary factor time series as exogenous variables with lags. To our best knowledge, none of these types of augmentation have been used in the literature so far.

In the empirical analysis, we report and compare impulse-response functions (IRFs) for the four acceding countries the Czech Republic, Hungary, Poland, and Slovakia. We identify monetary policy shocks using a recursive structure and document the role of external information by comparing the responses to contractionary monetary policy shocks from benchmark VARs with those of different FAVARs. We investigate the role of external information coming from EMU countries and of information coming from the other acceding countries, respectively. In other words, we use different FAVARs, either using the factor time series from EMU countries or using the factor time series from accession countries.

We find that including EMU factors does change impulse-response patterns in some but not all acceding countries. In contrast, including the acceding country information leads to more substantial changes in the impulse-response pattern. Compared with the benchmark model, the responses to a monetary policy shock are thus more in line with theoretical expectations: output variables tend to drop, prices tend to decrease (the price puzzle disappears or is less pronounced), and the exchange rate appreciates. In some countries, a reasonable monetary transmission mechanism can only be diagnosed when the external accession country factors are included in the model. Our results suggest that the external economic developments in the other acceding countries are more important for the monetary transmission than the economic goings-on in the Euro area. Overall, our results highlight the importance of taking these external developments properly into account. 
The remainder of the paper is organized as follows. In Section 2 we introduce the econometric framework. Section 3 contains the empirical results from the factor analysis as well as from the FAVAR impulse-response analysis. Section 4 concludes.

\section{THE ECONOMETRIC FRAMEWORK}

We use factor-augmented VAR models in the empirical analysis. Therefore, in Section 2.1 we briefly review the framework for the factor analysis, which corresponds to the first part of the empirical analysis in Section 3. How the factors enter the VAR and how we use this model to compute IRFs are explained in Section 2.2.

\subsection{Stationary and Nonstationary Factor Models}

Factor models that condense the information from a large cross section of time series have been introduced in the context of forecasting [see, e.g., Stock and Watson (2002a, 2002b)], and this framework has been extended by Bai (2004) and Bai and $\mathrm{Ng}$ (2004) to the case of nonstationary factors.

We assume that the $N$-dimensional time series $X_{t}$ is driven by a small number $L$ of unobserved common factors $F_{t}$ and an idiosyncratic component $e_{t}$; i.e., the vector of time series may be written as

$$
X_{t}=\Lambda F_{t}+e_{t}, \quad t=1, \ldots, T,
$$

where $X_{t}$ is an $N \times 1$ vector, $\Lambda$ is an $N \times L$ matrix of factor loadings, $F_{t}$ is the $L \times 1$ vector of common factors, and $e_{t}$ is an $N \times 1$ vector of idiosyncratic components. We follow Bai and $\mathrm{Ng}$ (2004) and allow for possible nonstationarity in both $F_{t}$ and $e_{t}$. If we use principal components to estimate this equation the estimates of the factors $F_{t}$ will not be consistent if the elements of $e_{t}$, denoted as $e_{i t}$, are I(1). Bai and $\mathrm{Ng}$ (2004) show that in this case, applying the method of principal components to the first-differenced data leads to consistent estimation of the factors. We prefer this over the alternative approach developed in Bai (2004), as this alternative requires that the idiosyncratic components be $\mathrm{I}(0)$ for consistent factor estimation. To be precise, we define $x_{t}=X_{t}-X_{t-1}=\Delta X_{t}$ for $t=2, \ldots, T$ and the $(T-1) \times N$ matrix of stationary variables $x=\left(x_{2}, \ldots, x_{T}\right)^{\prime}$, with the $t$ th row being $x_{t}^{\prime}$. Moreover, we let $f_{t}=F_{t}-F_{t-1}=\Delta F_{t}$, and $f=\left(f_{2}, \ldots, f_{T}\right)^{\prime}$ is the $(T-1) \times L$ vector of differenced factors. The principal components estimator of $f$ is given as

$$
\tilde{f}=\sqrt{T-1} V,
$$

where $V$ is the matrix of the $L$ eigenvectors corresponding to the $L$ largest eigenvalues of the matrix $x x^{\prime}$. The factors are normalized so that $\tilde{f}^{\prime} \tilde{f} /(T-1)=I_{L}$ holds, and we refer to these normalized factors as $\hat{f}$. Using this normalization, the 
loadings are estimated as

$$
\hat{\Lambda}=x^{\prime} \hat{f} /(T-1) .
$$

The corresponding estimator for $F_{t}$ is given by cumulating the stationary principal component factors $\hat{f}_{t}$, i.e.,

$$
\hat{F}_{t}=\sum_{s=2}^{t} \hat{f}_{s} .
$$

By using this approach we obtain estimates of the $F_{t}$, which retain their order of integration regardless of $e_{i t}$ being $\mathrm{I}(0)$ or $\mathrm{I}(1)$. We refer to equations (1) and (2) as the stationary and nonstationary factor time series, respectively.

\subsection{Factor-Augmented Vector Autoregressions}

The monetary transmission mechanism is analyzed within the VAR framework. The starting point is a standard VAR with intercept of the form

$$
y_{t}=v+A_{1} y_{t-1}+\cdots+A_{p} y_{t-p}+u_{t},
$$

where $y_{t}$ is a $K \times 1$ vector of endogenous variables, $v$ is a $K \times 1$ vector of intercepts, $A_{1}, \ldots, A_{p}$ are $K \times K$ fixed VAR coefficient matrices, and $u_{t}$ is the reduced-form innovation vector with mean zero and fixed nonsingular covariance matrix $\Sigma_{u}$. In what follows, we discuss the two variants of factor augmentation that we use in the empirical analysis.

The first approach follows the idea of Bernanke et al. (2005) and Stock and Watson (2005). In their set-up, the estimated stationary factor time series $\hat{f}_{t}$ are added as variables to a VAR model. In contrast to this, we include the nonstationary factor time series $\hat{F}_{t}$ in the VAR. Also note that in our application the group of variables from which the factors are extracted does not contain the variables $y_{t}$, as for a particular country we only use data from other foreign countries (EMU or other accession countries) for factor extraction. Our first setup is obtained by defining the $(L+K) \times 1$ vector as $y_{t}^{*}=\left(\hat{F}_{t}^{\prime}, y_{t}^{\prime}\right)^{\prime}$ and then formulating the factor-augmented VAR as

$$
y_{t}^{*}=v^{*}+A_{1}^{*} y_{t-1}^{*}+\cdots+A_{p}^{*} y_{t-p}^{*}+u_{t}^{*},
$$

where $A_{i}^{*}, i=1, \ldots, p$, are now $(L+K) \times(L+K)$ fixed coefficient matrices. ${ }^{2} u_{t}^{*}$ is now an $(L+K) \times 1$ innovation vector with covariance matrix $\Sigma_{u}^{*}$. Including the nonstationary factors in the model has the advantage that possible cointegration relationships between the factors $F_{t}$ and the VAR variables in $y_{t}$ are implicitly accounted for. In addition, in this approach the factor time series and $y_{t}$ are likely to be of the same order of integration, and hence we look at a type of balanced regression. If the errors in (4) follow a martingale difference sequence, estimation of the VAR with levels of the variables and the nonstationary factor time series seems warranted, given the points made by Sims et al. (1990). A potential problem 
of computing impulse responses from nonstationary VARs estimated in levels has been pointed out by Phillips (1998), who shows that convergence of impulseresponse estimators at longer horizons is not ensured. Hence, interpreting the responses at longer horizons should be done with some caution.

Alternatively, we include the factor time series in the form of exogenous variables. To be more precise, we use VAR models of the form

$$
y_{t}=v+A_{1} y_{t-1}+\cdots+A_{p} y_{t-p}+B_{0} \hat{F}_{t}+\cdots+B_{s} \hat{F}_{t-s}+u_{t},
$$

where $y_{t}$ is a $K \times 1$ vector of endogenous variables and $\hat{F}_{t}$ is the $L \times 1$ factor variable vector. $B_{0}, \ldots, B_{s}$ are fixed $K \times L$ coefficient matrices related to the exogenous variables. As before, $u_{t}$ is the reduced-form innovation vector with mean zero and fixed, nonsingular covariance matrix $\Sigma_{u}$. Estimation of the VAR in levels of the variables and the nonstationary factor time series seems warranted as long as $s \geq 1$ [see Sims et al. (1990)].

The VAR models given in (3)-(5) are reduced-form models. The effects of structural shocks are typically investigated using the structural VAR (SVAR) framework [see, e.g., Breitung et al. (2004) for an overview of these models]. In order to identify the monetary policy shocks, suitable restrictions have to be imposed on the model.

The basic idea in identification is that the reduced-form disturbances $u_{t}$ are regarded as linear combinations of a set of structural shocks $\varepsilon_{t}$, such that

$$
u_{t}=G \varepsilon_{t}
$$

Once the matrix $G$ has been determined, impulse responses to monetary policy shocks can be computed using the standard formulas laid out, e.g., in Lütkepohl (2005, Sect. 2.3).

We focus on the well-known recursive scheme in which $G$ is a lower triangular matrix obtained from a Choleski decomposition of the covariance matrix $\Sigma_{u}$. Clearly, with this recursive identification scheme, the results may depend on the ordering of the variables. In the empirical baseline model of Section 3 , we have a four-dimensional VAR model with $y_{t}=\left(q_{t}, p_{t}, r_{t}, e_{t}\right)^{\prime}$, where $q_{t}$ is the log of industrial production, $p_{t}$ is the log of the consumer price index $(\mathrm{CPI}), r_{t}$ is the short-term interest rate, and $e_{t}$ is the log of the exchange rate, measured as local currency per ECU/Euro. Monetary policy shocks are related to the equation in $r_{t}$, and therefore using the recursive scheme implies that monetary policy shocks may have an immediate impact on the exchange rate, whereas output and prices can only be affected with a lag of one period. This identification scheme is quite standard in the literature [see, e.g., Christiano et al. (1999)]. Once factor time series are included in the VAR as in (4), we order them first; i.e., we use $y_{t}^{*}=\left(\hat{F}_{t}^{\prime}, y_{t}^{\prime}\right)^{\prime}$. This implies that the interest rate shock in a particular acceding country has no immediate impact on external development in either the EMU or the other acceding countries. ${ }^{3}$ 


\section{EMPIRICAL RESULTS}

In this section we report empirical results on the effects of monetary policy shocks for the acceding countries the Czech Republic, Hungary, Poland, and Slovakia. For each country, we compare the results from the baseline specification without taking into account the external information and with those from models that include either EMU or acceding country factor time series.

\subsection{Data}

As mentioned earlier, the baseline VAR model specification for an acceding country is a four-dimensional VAR model with $y_{t}=\left(q_{t}, p_{t}, r_{t}, e_{t}\right)^{\prime}$, where $q_{t}$ is the $\log$ of industrial production, $p_{t}$ is the log of the consumer price index (CPI), $r_{t}$ is the short-term interest rate, and $e_{t}$ is the $\log$ of the exchange rate measured as local currency per ECU/Euro. For each country, monthly time series data ranging from 1995M01 to 2013M12 have been used in the baseline specification. To investigate possible changes due to the financial crisis in 2008/2009, we have also looked at results using a sample that ended in 2007M12 and discuss some of the results below. Precise data sources are given in the Appendix. Time series plots for the acceding country data series are given in Figure 1. It is obvious from the time series plots that at least some variables show trending behavior. A unit root analysis (results not shown) indicates that the unit root hypothesis cannot be rejected for all the considered time series and that most of them can be characterized as integrated of order 1, I(1). Against the background that the variables may be cointegrated, we follow the standard practice in this line of the literature and specify VAR models for the levels of the variables. This avoids the false cancellation of long-run relationships between the variables. Also note that the beginning of the sample is characterized by more volatile movements, e.g., in interest rates, most likely due to effects related to transitional processes. For instance, the Czech Republic and Slovakia abandoned fixed exchange rates to the Deutsche Mark, an inflation-targeting framework was adopted by the Czech national bank in December 1997, and in October 1998 a similar policy was adopted by the National Bank of Slovakia. ${ }^{4}$

To account for external influences, we extract factor time series (a) from a large set of macroeconomic time series from EMU countries and (b) from sets of acceding countries. To extract the EMU factors we use data from 11 EMU member states $^{5}$ on industrial output, CPI and producer price index, short- and long-term interest rates, exchange rates, share prices, unemployment, imports, and exports. Again, the data sources are listed in the Appendix. The EMU data set is composed of 108 time series. $^{6}$

Correspondingly, for a similar set of variables, we collect data for the four acceding countries, the Czech Republic, Hungary, Poland, and Slovakia. The list of variables coincides with the one given for the EMU countries, except that we 

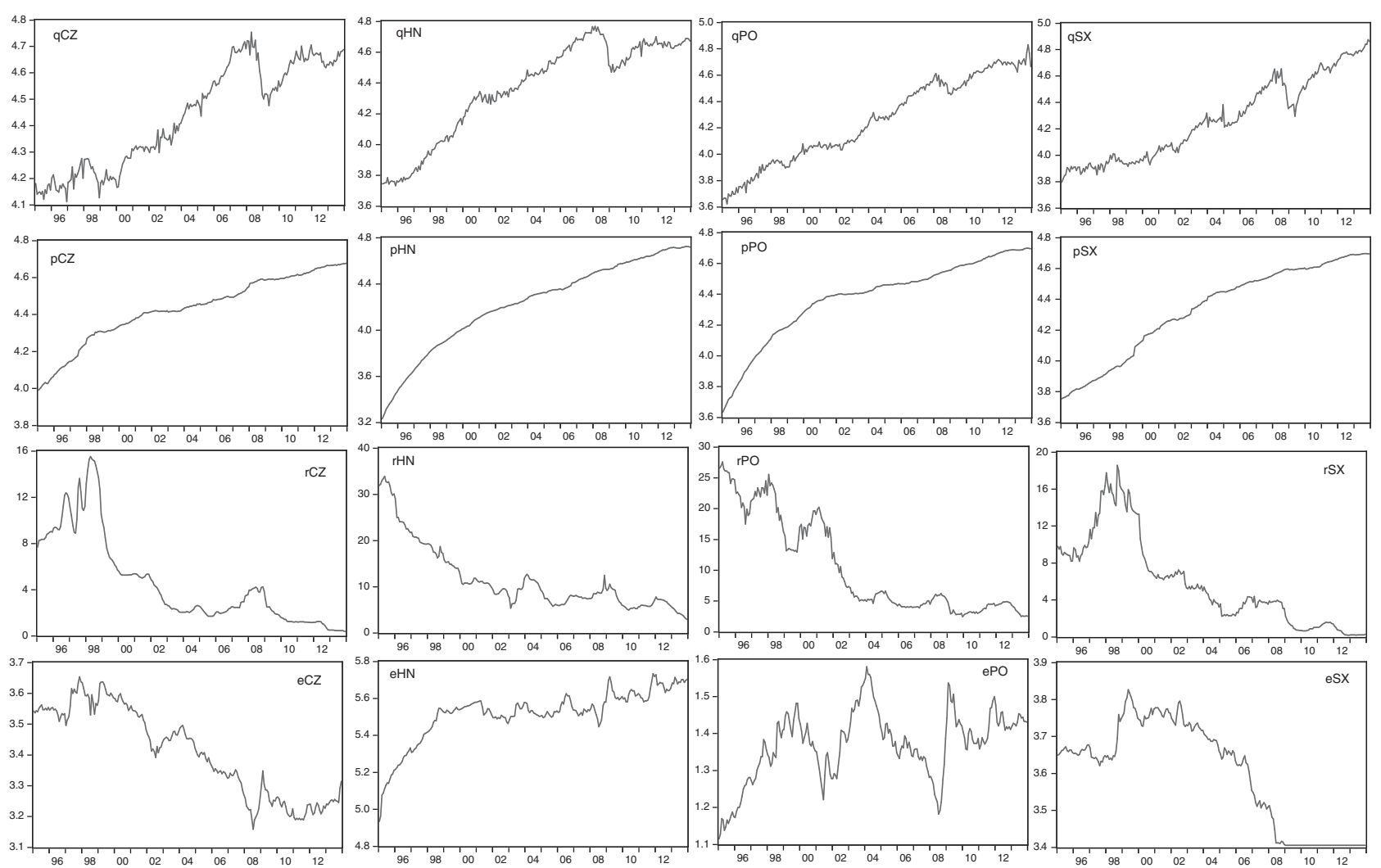

FigURE 1. Time series plots for the Czech Republic, Hungary, Poland, and Slovakia, 1995M01-2013M12: the log of industrial production $\left(q_{t}\right)$, the $\log$ of the consumer price index $\left(p_{t}\right)$, the short-term interest rate $\left(r_{t}\right)$, and the log of the exchange rate measured as local currency per ECU/Euro $e_{t}$. 
TABLE 1. Variable groups and their transformations

\begin{tabular}{ll}
\hline Variable group & \multicolumn{1}{c}{ Transformation } \\
\hline IP & First difference of logs \\
UN & First difference \\
IMP & First difference of logs \\
EXP & First difference of logs \\
CPI & First difference of logs \\
PPI & First difference of logs \\
RS & First difference \\
RL & First difference \\
EXR & First difference of logs \\
SP & First difference of logs \\
\hline
\end{tabular}

TABLE 2. Cumulative proportion of explained variance

\begin{tabular}{lcccccccc}
\hline & $(1)$ & $(2)$ & $(3)$ & $(4)$ & $(5)$ & $(6)$ & $(7)$ & $(8)$ \\
& $\begin{array}{c}\text { EMU } \\
\text { all }\end{array}$ & $\begin{array}{c}\text { EMU } \\
\text { all }\end{array}$ & $\begin{array}{c}\text { EMU } \\
\text { core }\end{array}$ & $\begin{array}{c}\text { EMU } \\
\text { core }\end{array}$ & $\begin{array}{c}\text { ACC } \\
\text { w/o HN }\end{array}$ & $\begin{array}{c}\text { ACC } \\
\text { w/o CZ }\end{array}$ & $\begin{array}{c}\text { ACC } \\
\text { w/o PO }\end{array}$ & $\begin{array}{c}\text { ACC } \\
\text { w/o SX } \\
95-13\end{array}$ \\
\hline 1 & $95-07$ & $95-13$ & $95-07$ & $95-13$ & $95-13$ & $95-13$ & $95-13$ \\
\hline 2 & 0.179 & 0.156 & 0.220 & 0.182 & 0.155 & 0.169 & 0.158 & 0.187 \\
3 & 0.301 & 0.274 & 0.363 & 0.320 & 0.275 & 0.273 & 0.262 & 0.323 \\
4 & 0.363 & 0.330 & 0.455 & 0.401 & 0.359 & 0.354 & 0.333 & 0.415 \\
5 & 0.422 & 0.382 & 0.524 & 0.470 & 0.426 & 0.429 & 0.400 & 0.482 \\
6 & 0.470 & 0.428 & 0.587 & 0.537 & 0.484 & 0.487 & 0.457 & 0.528 \\
& 0.501 & 0.462 & 0.638 & 0.596 & 0.536 & 0.536 & 0.511 & 0.572 \\
\hline
\end{tabular}

Notes: Table shows cumulative proportion of the variance explained by the number of factors listed in the column "Factor." EMU (all) refers to data from 11 EMU countries; EMU (core) refers to data from Germany, France, and Italy only. ACC refers to data from the acceding countries.

have no observations of the long-term interest rates. Thus for each country we have only nine variables available.

\subsection{EMU and Acceding Country Factor Time Series}

For the factor extraction step, the time series have to be transformed to stationarity. We follow the standard practice in the factor literature [see, e.g., Stock and Watson (2002b)] and transform the variables to stationarity by taking either first differences or first differences of the logarithm. The corresponding transformation codes can be found in Table $1 .^{7}$ The transformed data are then demeaned and normalized to have unit variance before the principal components are extracted. For the different factor models used in this paper, Table 2 reports the cumulative proportion of the variance explained by the first six principal components. 
Factor time series from EMU data. Starting with the EMU data set, the information criteria of Bai and $\mathrm{Ng}$ (2002) point to up to six factors. As indicated in column (1) of Table 2, the first six factors explain about $50 \%$ of the variance in the EMU data set in the 1995-2013 sample. ${ }^{8}$ Note that the fit of the factor model in the shorter subsample is quite comparable [see column (2) of Table 2]. Moreover, we checked whether using only a subset of data coming from the three largest core EMU economies (Germany, France, Italy) would improve the fit of the factor model. As can be seen from columns (3) and (4) of Table 2, the fraction of the variance explained is slightly larger when only data from the core EMU are used. This is to be expected, given that the number of variables used is now substantially smaller. Note, however, that the results from scree plots (not reported in the paper) do not suggest any substantial advantage of the factor model for core EMU data. Moreover, it turned out that using either all or only core EMU data for factor extraction does not have any substantial impact on the following impulseresponse exercise. Therefore, we focus on using factor time series obtained from using all EMU data. ${ }^{9}$

To give some insight into what the principal components represent, we would like to relate these factor series to the original time series data from which the factors have been extracted. Clearly, the factors are only identified up to a rotation, and here we use a standard statistical normalization that is used in the FAVAR context [cf., e.g., Bernanke et al. (2005)]. Given this normalization, we try to relate these factor series to different economic time series. Evidently, the corresponding factor interpretation should be regarded with some caution and is only tentative, as it is not based on a structural model. Nevertheless, the results based on this approach are still helpful to understand the results from the impulse-response analysis in Section 3.3. In order to get a better understanding of what these factors represent, we use a simple $R^{2}$ measure that has also been used by Stock and Watson (2002b). In this approach, the individual stationary factor series $\hat{f}_{t}$ are regressed on each of the $i=1, \ldots, N$ series $x_{i t}$ used in the factor extraction step and the $R^{2}$ of the corresponding regressions are reported. The results for the EMU factor series and the 108 (stationarity transformed) variables in the original data set are depicted in Figure 2 and show an interesting pattern. The first factor seems to be an important determinant of imports, exports, and the exchange rate. Thus we refer to this factor tentatively as the trade-related factor. The second factor influences most strongly the two interest rates, the exchange rate, and prices and might be a factor driving nominal variables. The third factor has relatively large $R^{2}$ in regressions on share prices and consequently might be referred to as a financial factor. Factor 4 shows a high correlation only with long-term interest rates, and the interpretation of the remaining factors is less clear. We also note that similar results are obtained for the shorter sample ending in 2007. Given that we do not have a fully structural factor model, we use up to all six factor time series in the FAVAR analysis.

Factor time series from acceding ccountry data. When analyzing the monetary transmission of policy shocks for a particular acceding country, we would like 

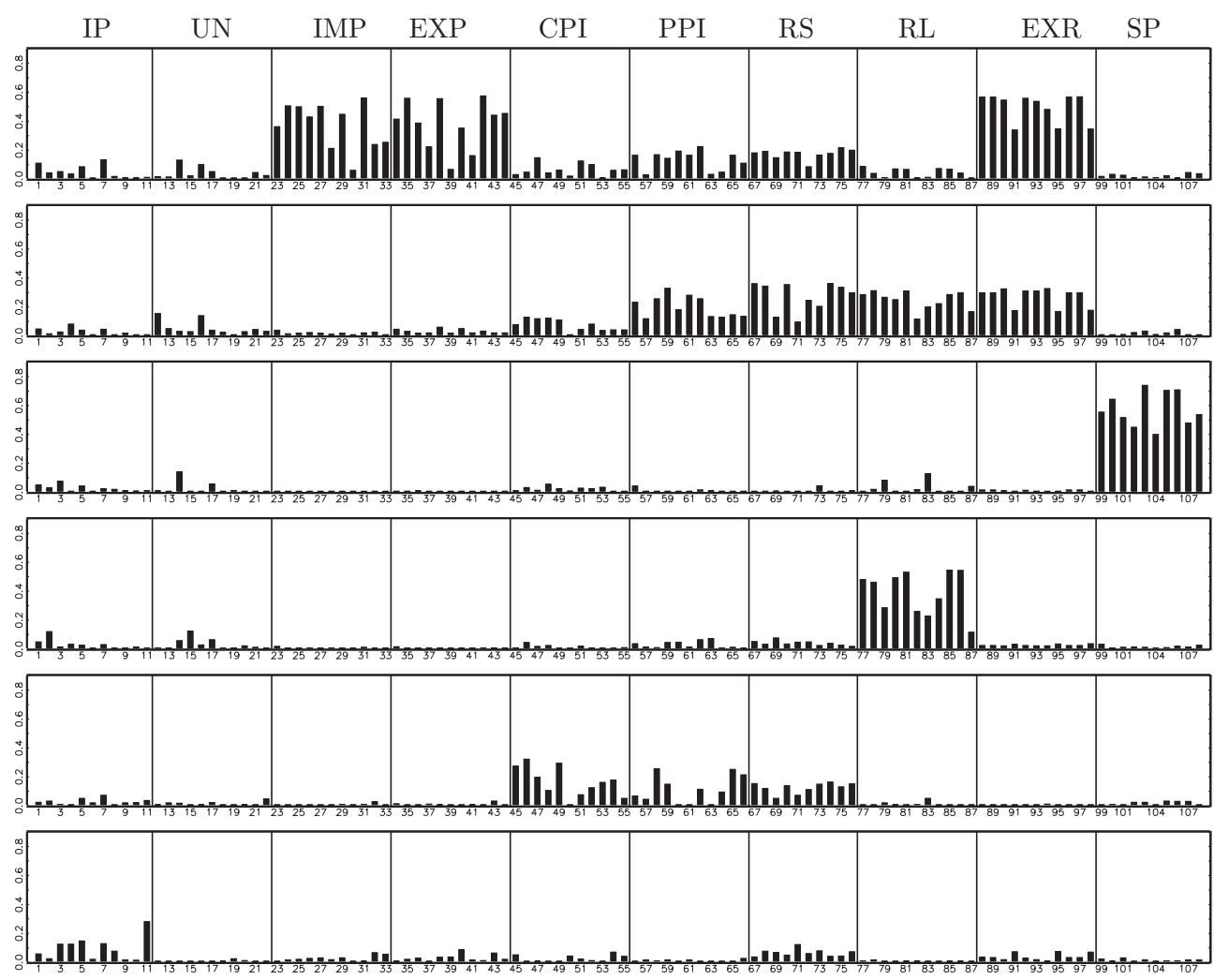

FIGURE 2. $R^{2}$ from regressions of the first six stationary factor time series on the individual stationary-transformed EMU time series. Row 1: $\hat{f}_{1}^{\mathrm{EMU}}, \ldots$, row 6: $\hat{f}_{6}^{\mathrm{EMU}}$. Groups of variables: industrial production (IP), unemployment (UN), imports (IMP), exports (EXP), consumer and producer prices (CPI and PPI), short- and long-term interest rates (RS and RL), exchange rates (EXR), share prices (SP). Sample period: 1995M01-2013M12. 
to explore the role of external developments in the other acceding countries. In order not to mix internal and external developments, we do not use data from the country under investigation when we extract the factors. For example, we augment the VAR model for the Czech Republic (CZ) used in Section 3.3 with factor time series that have been extracted using only data from Hungary, Poland, and Slovakia (HN, PO, SX). Thus, we extract separately factors from the following four sets of country combinations: (HN, PO, SX), (CZ, PO, SX), (CZ, HN, SX), (CZ, HN, PL). We summarize the ability of the factor models to explain the variation in the data in columns (5)-(8) of Table 2.

Although the information criteria of Bai and $\mathrm{Ng}$ (2002) suggest at most three factors, we report in Table 2 the cumulative proportion of the variance explained by the respective first six principal components. The first six principal component factors explain between $51 \%$ and $57 \%$ of the variance in the respective data collections. Again, we look at the $R^{2}$ in regressions of acceding country variables on acceding country factor time series. Figure 3 shows typical results for factors extracted from $\mathrm{CZ}, \mathrm{HN}$, and PO. We find that the first principal component (factor) seems to reflect a trade-related factor with typically large $R^{2}$ in imports, exports, and exchange rates. The second factor typically correlates highly with the price measures and hence may be referred to as a price/inflation factor. The third factor may tentatively be associated with share prices.

Overall, we expect that the factor time series extracted from EMU and acceding country data may be important in VARs used for analyzing the monetary transmission mechanism.

\subsection{FAVARs and the Response to Monetary Policy Shocks}

To analyze and compare the effects of contractionary monetary policy shocks, we start with baseline VAR models for $y_{t}=\left(q_{t}, p_{t}, r_{t}, e_{t}\right)^{\prime}$, where $q_{t}$ is the log of industrial production, $p_{t}$ is the $\log$ of the consumer price index $(\mathrm{CPI}), r_{t}$ is the short-term interest rate, and $e_{t}$ is the log of the exchange rate, measured as local currency per ECU/Euro. As explained earlier, we use monthly data over the sampling period from 1995M01 to 2013M12 in our baseline specifications. This sample is governed by data availability. For the Czech Republic, Hungary, and Poland, we also consider a shorter subsample ending at the end of 2007 to see whether excluding the period of the 2008/2009 financial crisis has a substantial impact on our results. For Slovakia, we only report VAR results for a sample ending in 2008 (before the adoption of the Euro). The VARs always include an intercept and the lag length is determined using the Akaike information criterion (AIC); see, e.g., Akaike (1974) and Lütkepohl (2005, Chap. 4). The results point to using $p=3$ lags for the Czech Republic and Poland, whereas two lags are suggested for Hungary and Slovakia. Nevertheless, we decided to use $p=3$ for Hungary and $p=4$ for Slovakia, as this helped to render the residuals free of autocorrelation. 

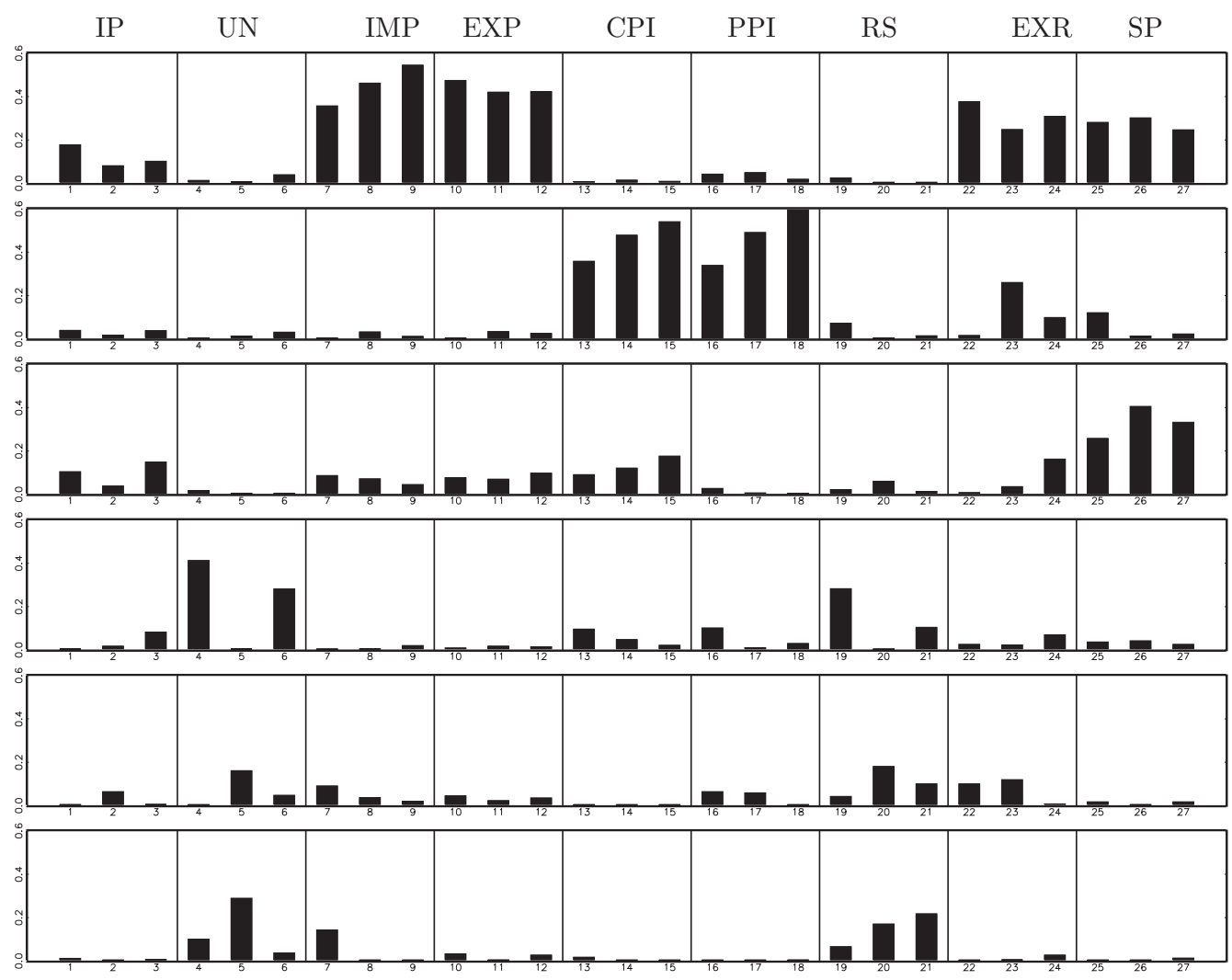

FIGURE 3. $R^{2}$ from regressions of the first six acceding country stationary factor time series on the stationary-transformed acceding country data time series. Row 1: $\hat{f}_{1}^{\text {ACC }}, \ldots$, row 6: $\hat{f}_{6}^{\text {ACC }}$. Factors are extracted without using data from Slovakia. Groups of variables: industrial production (IP), unemployment (UN), imports (IMP), exports (EXP), consumer and producer prices (CPI and PPI), short-term interest rates (RS), exchange rates (EXR), share prices (SP). Sample period: 1995M01-2013M12. 
TABLE 3. Estimated VAR and FAVAR models

\begin{tabular}{|c|c|c|c|c|c|c|c|c|}
\hline \multirow{6}{*}{$\begin{array}{l}\text { Factors } \\
\text { FA as in eq. } \\
\text { No. of factors (AIC) } \\
p \text {-value } \operatorname{LM}(2)\end{array}$} & \multicolumn{8}{|c|}{ Czech Republic } \\
\hline & \multicolumn{5}{|c|}{ 1995M01-2013M12 } & \multicolumn{3}{|c|}{ 1995M01-2007M12 } \\
\hline & - & EMU & EMU & $\mathrm{ACC}$ & $\mathrm{ACC}$ & - & $\mathrm{ACC}$ & ACC \\
\hline & - & (4) & $(5)$ & (4) & (5) & - & (4) & (5) \\
\hline & - & 1 & 5 & 1 & 6 & - & 1 & 3 \\
\hline & 0.158 & 0.237 & 0.012 & 0.083 & 0.031 & 0.331 & 0.174 & 0.006 \\
\hline & \multicolumn{8}{|c|}{ Hungary } \\
\hline & \multicolumn{5}{|c|}{ 1995M01-2013M12 } & \multicolumn{3}{|c|}{ 1995M01-2007M12 } \\
\hline \multirow{6}{*}{$\begin{array}{l}\text { Factors } \\
\text { FA as in eq. } \\
\text { No. of factors (AIC) } \\
p \text {-value } \operatorname{LM}(2)\end{array}$} & - & EMU & EMU & $\mathrm{ACC}$ & $\mathrm{ACC}$ & - & $\mathrm{ACC}$ & ACC \\
\hline & - & (4) & (5) & (4) & $(5)$ & - & (4) & (5) \\
\hline & - & 1 & 3 & 1 & 4 & - & 1 & 6 \\
\hline & 0.228 & 0.373 & 0.003 & 0.520 & 0.050 & 0.309 & 0.906 & 0.588 \\
\hline & \multicolumn{8}{|c|}{ Poland } \\
\hline & \multicolumn{5}{|c|}{ 1995M01-2013M12 } & \multicolumn{3}{|c|}{ 1995M01-2007M12 } \\
\hline Factors & - & EMU & EMU & ACC & $\mathrm{ACC}$ & - & ACC & ACC \\
\hline FA as in eq. & - & (4) & (5) & (4) & (5) & - & (4) & $(5)$ \\
\hline No. of factors (AIC) & - & 1 & 5 & 1 & 4 & - & 1 & 6 \\
\hline$p$-value $\operatorname{LM}(2)$ & 0.207 & 0.113 & 0.006 & 0.234 & 0.214 & 0.202 & 0.514 & 0.490 \\
\hline \multicolumn{9}{|c|}{ Slovakia } \\
\hline \multicolumn{9}{|c|}{ 1998M01-2008M12 } \\
\hline Factors & - & EMU & EMU & ACC & $\mathrm{ACC}$ & & & \\
\hline FA as in eq. & - & (4) & $(5)$ & (4) & $(5)$ & & & \\
\hline No. of factors (AIC) & - & 1 & 1 & 1 & 6 & & & \\
\hline$p$-value $\mathrm{LM}(2)$ & 0.751 & 0.410 & 0.459 & 0.343 & 0.274 & & & \\
\hline
\end{tabular}

Notes: Estimated VARs for the Czech Republic, Hungary, and Poland: VAR(3). Estimated VAR for Slovakia: VAR(4). The table reports the type of factors included (EMU factors vs. acceding country factors), the way factors are included in the VAR [either as in (4) or as in (5)], and the number of factors as selected by AIC. " $p$-value $\operatorname{LM}(2)$ " refers to the $p$-value of the multivariate LM-test for remaining residual autocorrelation at lag 2 .

In addition to results from this baseline specification, we also report results for FAVAR models, in which the nonstationary factor time series $\hat{F}_{t}$ enter either endogenously or exogenously, as explained in Section 2.2. The number of factors included in the VAR models has been determined using the AIC. We select among FAVAR models with the number of factors ranging between one and six. If this factor enters exogenously, we include the contemporaneous value and its first lag, i.e., $s=1$ in (5). ${ }^{10}$ Table 3 provides an overview of the estimated models with details on the number of included factors and tests for remaining residual autocorrelation. Note that the AIC suggests using one endogenous factor for all 
model specifications considered. In contrast, the suggested number of exogenously included factors ranges between two and six, depending on the country and whether EMU factors or acceding country factors are considered. The results of residual autocorrelation tests indicate no strong evidence for remaining residual correlation for most of the specified models, with some exceptions for FAVAR models with exogenous EMU factors. Thus, the estimated VAR models seem to be reasonably well specified to warrant the approach advocated by Sims et al. (1990).

To facilitate comparison between impulse responses obtained from different models, we provide plots of asymptotic confidence intervals with nominal coverage of $90 \%$ from the benchmark, as well as the two factor-augmented VARs. ${ }^{11}$

Figures 4-7 show the intervals for impulse responses to a contractionary monetary policy shock (with a size of one standard deviation) using the benchmark VAR, the FAVAR with endogenous factors, and the FAVAR with exogenous factors. The first column in each figure reports results of VARs with EMU factors, whereas the second column shows results of VARs with accession country factors. The first two columns refer to the baseline sample period (1995-2013). The last column reports results of VARs with acceding country factors for the reduced sample (1995-2007). All columns also include the intervals from the benchmark VAR without factors to facilitate the comparison. The discussion of the results follows along the four different countries.

The results for the Czech Republic show that the inclusion of one EMU factor time series as an endogenous variable does not change the results greatly compared with those for the benchmark VAR [see column (1) of Figure 4]. Following the monetary policy shock, output drops significantly after about six months. The exchange rate tends to appreciate (negative response) about one and one-half years after the shock; however, the effect is only borderline significant. Including five EMU factors exogenously as in (5) changes the responses of output and exchange rate somewhat. The drop in output is now slightly smaller but still significantly different from zero. The long-run response of the exchange rate is no longer significantly different from zero. Despite these small changes, the overall interpretation of the impulse responses does not change if EMU factors are included in the model. In particular, a significant price puzzle for the first six months after the monetary policy shock is observed even when the EMU factor time series are included. Column (2) of Figure 4 shows the responses to a monetary policy shock from models that add acceding country factors to the benchmark specification. Adding one acceding country factor endogenously to the VAR does not change the results from those for the benchmark VAR. In contrast, using six factors exogenously clearly changes the results. In particular, although a significantly negative response in output persists, the price puzzle vanishes. The positive response of prices in the first few periods after the shock is no longer significant. For this FAVAR variant a clearly significant and persistent negative response of prices is observed after about six months, which was not observed in the benchmark model. Moreover, in the model with exogenous acceding country factors, the appreciation of the exchange rate is somewhat more pronounced and 

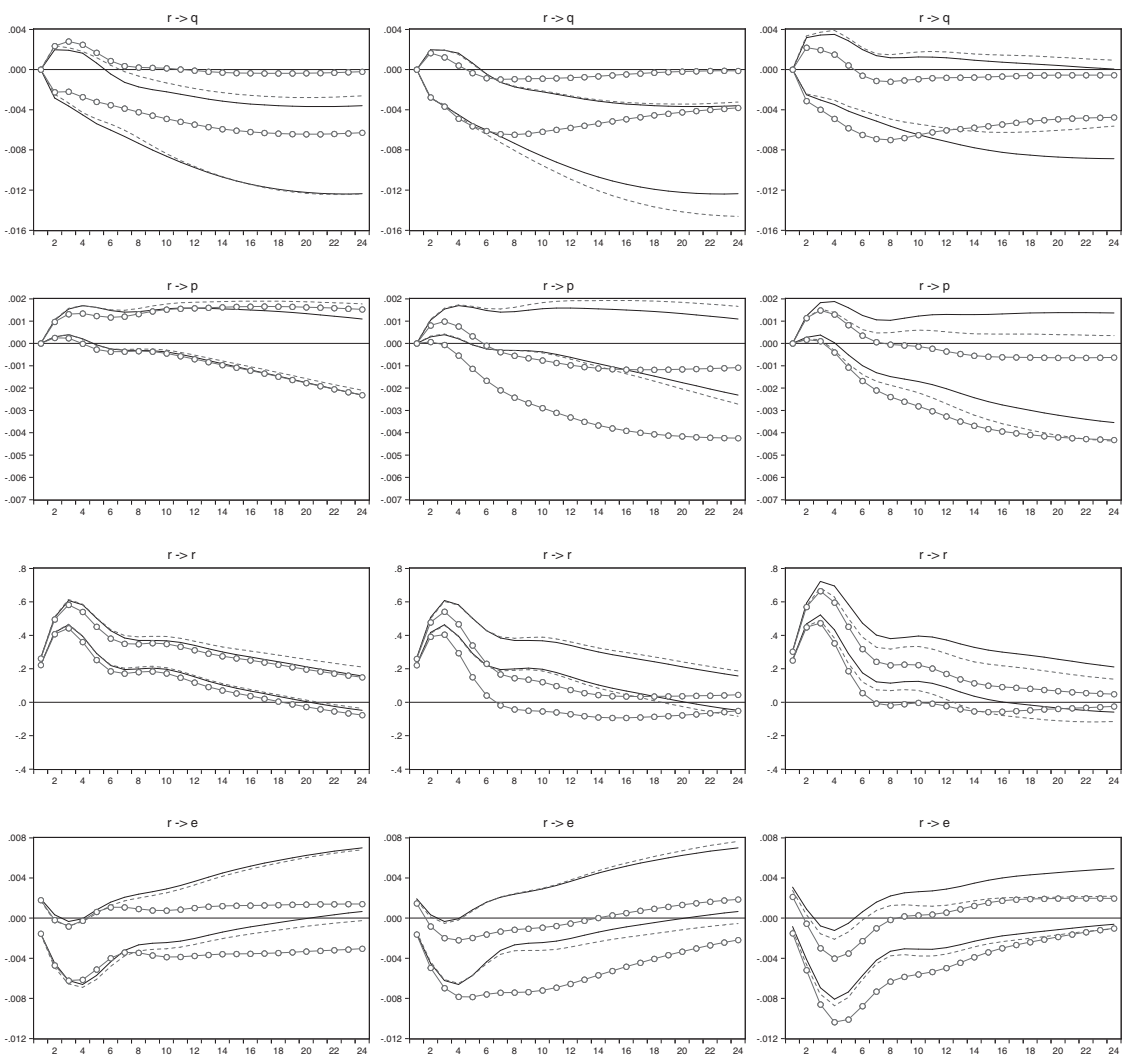

FIGURE 4. Czech Republic: $90 \%$ confidence intervals of responses to a contractionary monetary policy shock in benchmark VAR(3) (solid lines), FAVAR(3) with endogenous factors (dashed lines), and FAVAR(3) with exogenous factors (lines w. circles). Left column: FAVARs using EMU factors, 1995M01-2013M12. Middle column: FAVARs using acceding country factors, 1995M01-2013M12. Right column: FAVARs using acceding country factors, 1995M01-2007M12. Numbers of factors used are given in Table 3.

now is clearly significant for more than a year. Note that although we have not imposed any sign restrictions, the model using the external information from the other accession countries does not show the price puzzle and the responses are now in line with what to expect from economic theory. Obviously, accounting for developments in the other acceding countries seems more important than accounting for developments in the EMU.

The last column in Figure 4 shows results from FAVAR models with acceding country factors for the reduced sample ranging from 1995 to 2007, excluding the recent 2008/2009 financial crisis period. First we note that the benchmark specification without factors now no longer indicates a significant drop in output after a contractionary monetary policy shock. In contrast, using the FAVAR model 

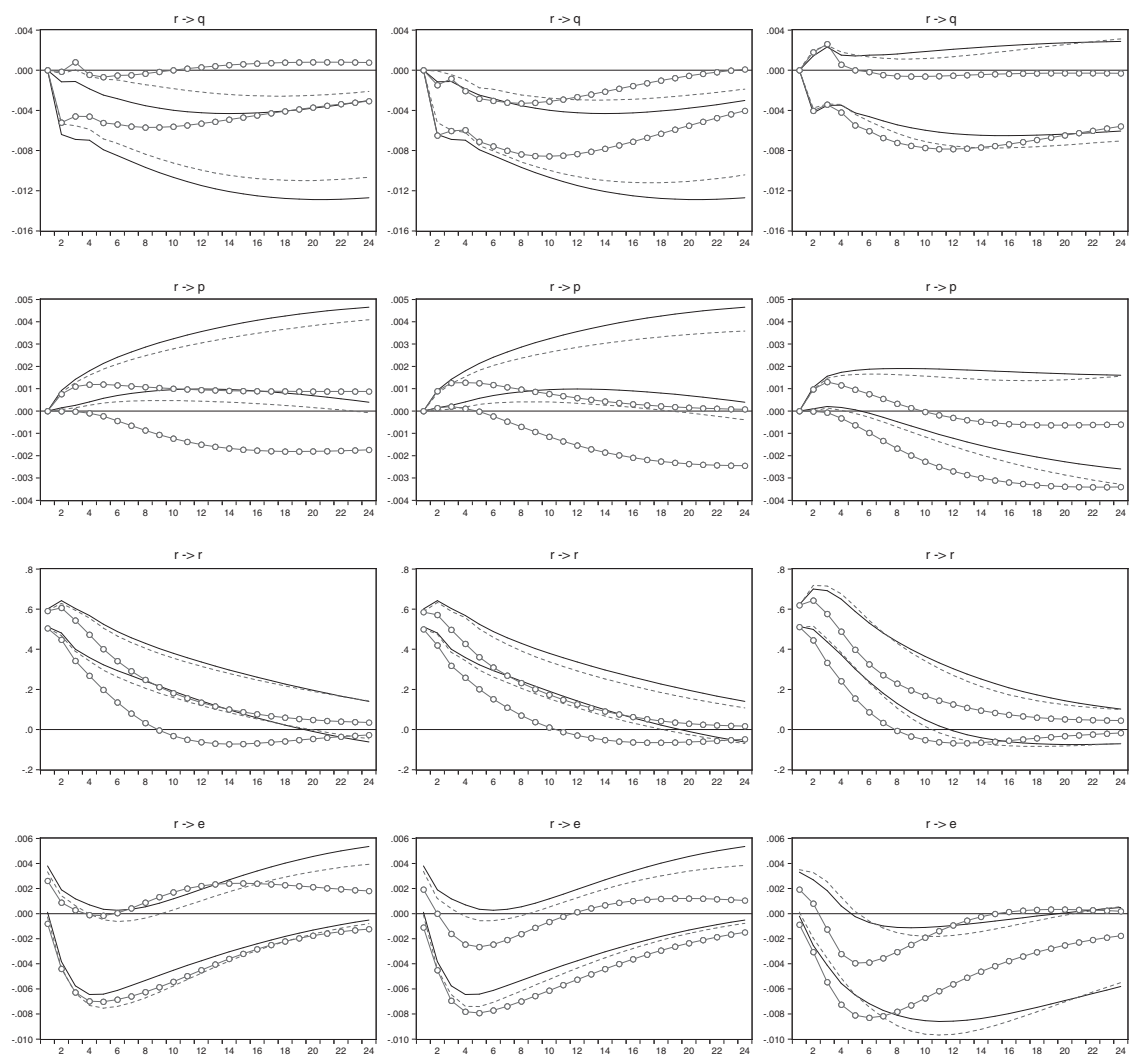

FIGURE 5. Hungary: $90 \%$ confidence intervals of responses to a contractionary monetary policy shock in benchmark VAR(3) (solid lines), FAVAR(3) with endogenous factors (dashed lines), and FAVAR(3) with exogenous factors (lines w. circles). Left column: FAVARs using EMU factors, 1995M01-2013M12. Middle column: FAVARs using acceding country factors, 1995M01-2013M12. Right column: FAVARs using acceding country factors, 1995M01-2007M12. Numbers of factors used are given in Table 3.

with three exogenous factors, we still get a significant drop in output. Finally, it is interesting to note that the results for the FAVAR with exogenous factors remain virtually unchanged. We also have results for the 1995-2007 sample from FAVAR models with EMU factors. As there are only small changes in comparison to the results reported in column (1), we decided not to include them, to conserve space. ${ }^{12}$ Overall, the results for the 1995-2007 sample do not change the main message: Including the acceding country factor time series avoids the price puzzle and leads to more reasonable results than the benchmark VAR.

Figure 5 shows results for Hungary. The model without factors indicates a significant and persistent drop in output, a pronounced price puzzle, and no significant reaction of the exchange rate. Adding one EMU factor endogenously leaves 

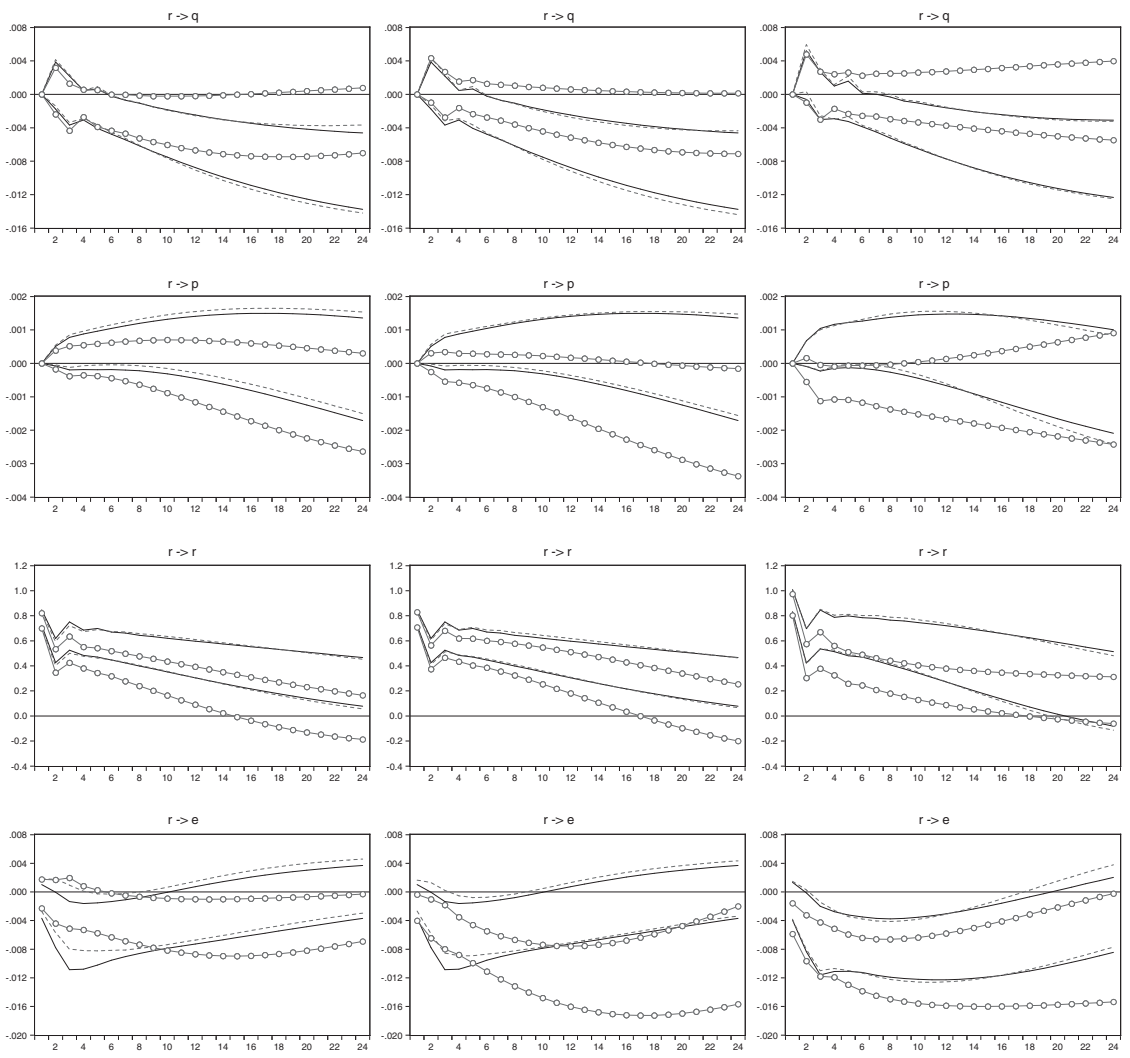

FIGURE 6. Poland: $90 \%$ confidence intervals of responses to a contractionary monetary policy shock in benchmark VAR(3) (solid lines), FAVAR(3) with endogenous factors (dashed lines), and FAVAR(3) with exogenous factors (lines w. circles). Left column: FAVARs using EMU factors, 1995M01-2013M12. Middle column: FAVARs using acceding country factors, 1995M01-2013M12. Right column: FAVARs using acceding country factors, 1995M01-2007M12. Numbers of factors used are given in Table 3.

the responses largely unchanged. In contrast, when three EMU factors are added exogenously, the output response is less pronounced and the price response is no longer significantly positive. Consequently, adding the EMU factor may at least help to avoid the price puzzle. If acceding country factors are added to the model [cf. column (2) of Figure 5], the output response is similar to the benchmark model. However, using the accession factors again avoids the price puzzle, and the exchange rate is now significantly appreciating after the monetary policy shock. Thus, the accession factors contain useful information in VARs analyzing the monetary policy transmission.

Column (3) of Figure 5 shows results for the 1995-2007 subsample from FAVARs with acceding country factors. First we note that the responses in the 

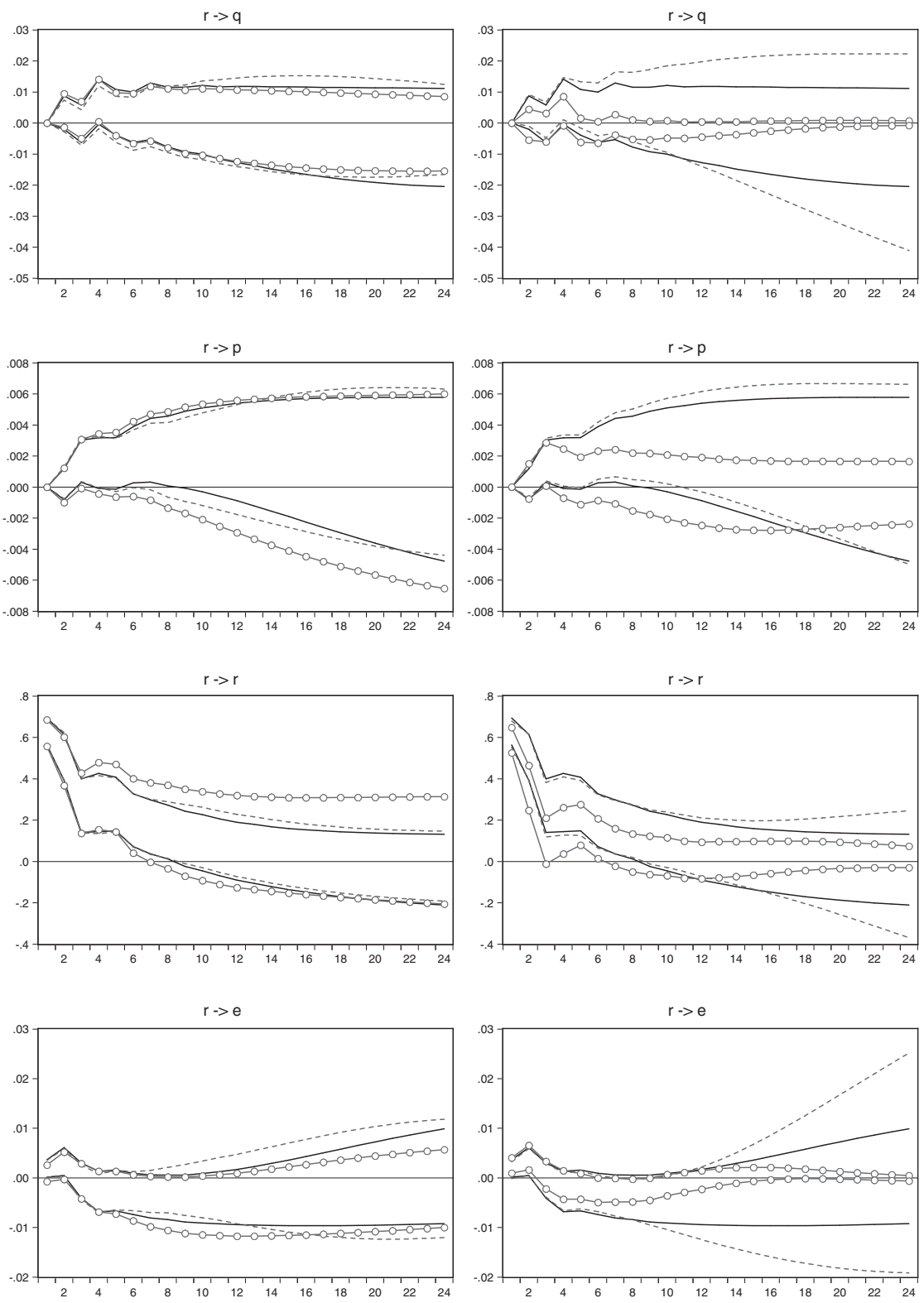

FIGURE 7. Slovakia: $90 \%$ confidence intervals of responses to a contractionary monetary policy shock in benchmark VAR(4) (solid lines), FAVAR(4) with endogenous factors (dashed lines), and FAVAR(4) with exogenous factors (lines w. circles). Left column: FAVARs using EMU factors, 1998M01-2008M12. Right column: FAVARs using acceding country factors, 1998M01-2008M12. Numbers of factors used are given in Table 3. 
benchmark have changed (compared with the full sample). This model without factors now indicates no significant reaction of output and only slightly increasing prices after the monetary policy shock, together with a significant appreciation of the exchange rate. This may partly reflect the larger estimation uncertainty in the shorter sample, but may also be an indication of changes in the monetary transmission mechanism due to the financial crisis. Note, however, that less severe changes are observed in the models with acceding country factors. In particular, the FAVAR variant with six exogenous factors still points to a significant (albeit less severe) drop in output and a significant appreciation of the exchange rate. We also note that this FAVAR variant now indicates a significant price drop after about a year. This again points to the fact that including acceding country factors is useful in analyzing the monetary transmission mechanism.

The results for Poland are given in Figure 6. In the benchmark VAR we find a significant and permanent drop in output after about six months. Prices do not react significantly. Moreover, the benchmark VAR indicates a significant appreciation of the exchange rate for little less than a year. The impact of adding EMU factors is shown in column (1) of Figure 6. In the model with one endogenous EMU factor, the response of the exchange rate is only marginally significant, and all other responses are virtually unchanged. Somewhat more pronounced changes are visible when five EMU factors enter the model exogenously. In that case, the drop in output is less pronounced and only marginally significant. Moreover, in contrast to the benchmark model, the exchange rate now appreciates after about a year and the response remains significant for about two years. The observed change of the exchange rate response is in line with our traderelated interpretation of the EMU factor time series. In comparison with the results for Czech Republic and Hungary, we note more pronounced changes when EMU factors are added to the model. This may indicate that Poland is affected more strongly by external developments in the EMU than the other acceding countries.

The effect of adding acceding country factors is depicted in column (2) of Figure 6. Again, adding one factor endogenously does not greatly change the results from the benchmark. In contrast, using four exogenous acceding country factors leads to some interesting changes in the impulse-response pattern. First, no significant drop in output can be diagnosed. However, we see a significant negative response of prices after about 18 months and a much stronger and significant appreciation of the exchange rate with long-lasting effects.

Moving to the results for the 1995-2007 subsample [column (3) of Figure 6], we first note that the results from the benchmark VAR are quite similar to the full sample results. The only difference is visible for the response of the exchange rate, which is more persistent in the shorter subsample, indicating a significant appreciation for about 20 months. Again, adding accession factors changes the results somewhat: The output responses are less pronounced and not significant, and prices drop significantly for about eight months in the model with six exogenous acceding country factors. Overall, we find that adding acceding 
country factors may be particularly helpful in generating price responses that are in line with economic theory.

Figure 7 shows the results for Slovakia. Note that the figure reports results for a sample ranging from 1998M01 to 2008M12. Using data from 1995 as the beginning of the sample period results in a completely unreasonable impulse-response pattern with strongly increasing prices and a strong depreciation of the exchange rate. This may be due to model mis-specification in the rather volatile periods from 1995 to 1997 , where market interest rates fluctuated strongly. The sample for Slovakia ends in 2008, as the country adopted the Euro on January 1, 2009. Consequently, for Slovakia we only report results for one sample period. ${ }^{13}$ The impulse responses from the baseline model are not very informative. Responses to output, prices, and the exchange rate are not significant. Similarly to the results for the Czech Republic, adding the EMU factors [column (1)] does not alter the response patterns in a substantial way. The situation is again somewhat different if the acceding country factors are added [see column (2) of the figure]. Note that including one acceding country factor endogenously does not change the interpretation of the results. The reported confidence intervals, however, reflect the high estimation uncertainty for large impulse-response horizons in the rather short sample. Also, note that including six acceding country factors exogenously changes the reported response intervals substantially. They are now substantially smaller than in the model without factors, which indicates that there is substantial information content in these factors. The significant price puzzle observed in the benchmark model disappears. Nevertheless, the effects on output and exchange rate are at best borderline significant, possibly because of the very short sample period. Because of the rather short sample period, the results for Slovakia should be interpreted with some caution.

We have also computed responses to monetary policy shocks that are identified by contemporaneous sign restrictions as in Jarocinski (2010) as a robustness check. Because the analysis leads to qualitatively similar results, we have omitted this part from the paper. We just remark here that in some cases using contemporaneous sign restrictions leads to impulse responses that are somewhat less informative, with relatively wide error bands.

In summary, our results highlight the importance of taking external developments properly into account when analyzing the monetary transmission mechanism in acceding countries. First, we find that information contained in factor time series obtained from EMU country data changes impulse-response patterns in some but not all countries. Interestingly, for the Czech Republic and Slovakia, including EMU factors has no substantial impact. In contrast, for Hungary and Poland, the responses of some variables change. Because there are no large differences between the countries in terms of the trade market shares with the EMU, this factor alone is unlikely to explain the differences. In fact, explaining these difference in detail would require a more structural approach and a more detailed analysis, which is beyond the scope of this paper and left for future research. 
Moreover, we find evidence for a major role of external development in other acceding countries. Typically, including the other acceding countries' information leads to substantial changes in the impulse-response pattern. Compared with the benchmark model, the responses to a monetary policy shock are more in line with theoretical expectations: output variables tend to drop, prices tend to decrease (the price puzzle disappears or is less pronounced), and the exchange rate appreciates. In some countries, a reasonable monetary transmission mechanism can only be diagnosed when the external acceding country factors are included in the model. Our results suggest that for the analysis of monetary policy shocks, the external economic developments in the other acceding countries are more important than the economic developments in the Euro area. This may reflect the traditionally close links in trade among the countries under consideration.

\section{CONCLUSIONS}

We investigated the effects of monetary policy shocks in the Czech Republic, Hungary, Poland, and Slovakia within small VAR models. In particular, we explored to what extent accounting for external economic developments in the EMU and in other acceding countries changed the results from structural VAR models.

The external developments in the EMU are summarized by extracting factor time series using principal components from a relatively large database with time series data from 11 EMU countries. To tentatively interpret the extracted factor time series, we use a traditional $R^{2}$ measure. This suggests that the first EMU factor can be interpreted as a trade-related factor, as it is most closely related to imports, exports, and the exchange rate. We interpret the second factor as a driving factor for nominal variables and the third factor as a financial factor. Using a large cross section of time series on similar variables from the acceding countries, we find that the first principal component may again be interpreted as a trade-related factor, whereas the second one could be seen as a price/inflation factor. Because we do not have a fully structural model, we use up to six factor series to augment the VARs for the acceding countries.

To explore the role of external information in monetary analysis, we augment standard VAR models either with the factor series extracted from EMU data or with factors from acceding country data, and compare the results. Factor-augmented VARs (FAVARs) are specified in two different ways: First, we include the factors as endogenous variables in the VARs. Although the principal idea follows Bernanke et al. (2005), we use the nonstationary factors from the Bai and Ng (2004) approach in the VAR to preserve any cointegration relations among the variables and the factors. In a second variant, we include the nonstationary factor series as exogenous variables, which leads to more parsimonious models. To our best knowledge, none of these type of augmentations have been used in the literature so far.

We explore the role of external information by comparing the responses to contractionary monetary policy shocks from benchmark VARs with those of 
different FAVARs using data from 1995M01-2013M12. We find that information contained in factor time series obtained from EMU country data changes impulseresponse patterns in some but not all countries. For Hungary, including EMU factors exogenously avoids the price puzzle. Using EMU factors in the model for Poland changes the response of output and the exchange rate. Using EMU factors in models for the Czech Republic and Slovakia does not change the responses in any substantial way. Explaining these cross-country differences requires a more structural approach and is left for future research.

Interestingly, including the acceding country information leads to substantial changes in the impulse-response patterns. Compared with the benchmark model, the responses to a monetary policy shock are more in line with theoretical expectations: output variables tend to drop, prices tend to decrease (the price puzzle disappears or is less pronounced), and the exchange rate appreciates. In some countries, a reasonable monetary transmission mechanism can only be diagnosed when the external acceding country factors are included in the model. Thus, our analysis suggests that using the information from the other acceding countries leads to more important changes in the analysis of the monetary transmission mechanism than using the information from EMU countries. This result persists if a reduced sample excluding the 2008/2009 crisis is considered.

We have taken care implicitly of any cointegration relations among the variables by using nonstationary factors and variables in levels in the VAR models. Clearly, if cointegration is present, taking them explicitly into account would be beneficial. Modeling the monetary transmission mechanism in factor-augmented vector error models [see, e.g., Banerjee et al. (2014)] is therefore an interesting direction of future research.

\section{NOTES}

1. VAR-based impulse-response functions may not have been precisely estimated, given the relatively large number of parameters and the short time series data available. To mitigate this problem, Jarocinski (2010) suggests a Bayesian framework. See also Gavin and Kemme (2009) for a similar approach. Although this may help to reduce the estimation uncertainty, the problem of missing important variables cannot be resolved by this approach.

2. Note that the VAR orders in equations (3) and (4) are not necessarily the same.

3. As an alternative, we have also used contemporaneous sign restrictions as discussed in Jarocinski (2010) and comment briefly on the qualitatively similar results in Section 3.3.

4. Note that also Poland and Hungary have conducted monetary policy within an inflation-targeting scheme in recent years.

5. The countries used are the original 11 EMU members, Austria, Belgium, Finland, France, Germany, Italy, Ireland, Luxembourg, the Netherlands, Portugal, and Spain.

6. There are no series available for the short-term interest rate and share prices for Luxembourg. Consequently, the EMU data consist of 10 time series for each of 11 countries, minus two $(10 \times 11-2=$ 108).

7. The transformation applied is also backed up by a unit root analysis on the individual series.

8. Note that this number is quite comparable to what, e.g., Stock and Watson (2002b) found for U.S. data. In their paper the first six principal components explain about $39 \%$ of the variance in a slightly larger data collection. 
9. The results on impulse responses obtained using EMU factors extracted from core EMU countries are available on request.

10. Including at least one lag is necessary to capture the nonstationarity of the factors appropriately [see, e.g., the discussion of Sims et al. (1990)]. We have also tried more exogenous lags, but only the first lag entered the models significantly.

11. See (Breitung et al., 2004, Sect. 4.5) for details on the construction of impulse-response confidence intervals.

12. This also holds for the other countries. Consequently, for none of the countries are results for FAVARs with EMU factors for the 1995-2007 sample included in the paper.

13. We have also tried a shorter sample ending in 2007M12. The corresponding results are very similar to the ones in Figure 7. Therefore, we decided not to include them in this paper.

\section{REFERENCES}

Akaike, H. (1974) A new look at the statistical model identification. IEEE Transactions on Automatic Control AC-19(6), 716-723.

Angeloni, I., A.K. Kashyap, B. Mojon, and D. Terlizzese (2003) Monetary Transmission in the Euro Area: Does the Interest Rate Channel Explain It All? NBER working paper 9984.

Anzuini, A. and A. Levy (2007) Monetary policy shocks in the new EU members: A VAR approach. Applied Economics 39(9), 1147-1161.

Bai, J. and S. Ng (2002) Determining the number of factors in approximate factor models. Econometrica 70(1), 191-221.

Bai, J. and S. Ng (2004) A PANIC attack on unit roots and cointegration. Econometrica 72(4), $1127-$ 1177.

Bai, J.S. (2004) Estimating cross-section common stochastic trends in nonstationary panel data. Journal of Econometrics 122(1), 137-183.

Banerjee, A., M. Marcellino, and I. Masten (2014) Forecasting with factor-augmented error correction models. International Journal of Forecasting 30(3), 589-612.

Bernanke, B., J. Boivin, and P.S. Eliasz (2005) Measuring the effects of monetary policy: A factoraugmented vector autoregressive (FAVAR) approach. Quarterly Journal of Economics 120(1), 387422.

Breitung, J., R. Brüggemann, and H. Lütkepohl (2004) Structural vector autoregressive modeling and impulse responses. In H. Lütkepohl and M. Krätzig (eds.), Applied Time Series Econometrics, pp. 159-196. Cambridge, UK: Cambridge University Press.

Bussière, M., J. Fidrmuc, and B. Schnatz (2005) Trade Integration of Central and Eastern European Countries-Lessons from a Gravity Model. Working paper 545, European Central Bank.

Christiano, L.J., M. Eichenbaum, and C. Evans (1999) Monetary shocks: What have we learned and to what end?. In J. Taylor and M. Woodford (eds.), The Handbook of Macroeconomics, pp. 65-148. Amsterdam: Elsevier Science Publication.

Ciccarelli, M. and A. Rebucci (2002) The Transmission Mechanism of European Monetary Policy: Is There Heterogeneity? Is It Changing over Time? Working paper 02/54, International Monetary Fund.

Coricelli, F., B. Egbert, and R. MacDonald (2006) Monetary Transmission Mechanism in Central and Eastern Europe: Gliding on a Wind of Change. Working paper 850, Wiliam Davidson Institute, Ann Arbor, MI.

Dornbusch, R., C.A. Favero, and F. Giavazzi (1998) The immediate challenges for the European Central Bank. Economic Policy 26, 15-64.

Ehrmann, M., L. Gambacorta, J. Martinez-Pages, P. Sevestre, and A. Worms (2003) The effects of monetary policy in the euro area. Oxford Review of Economic Policy 19(1), 58-72.

Elbourne, A. and J. de Haan (2006) Financial structure and monetary policy transmission in transition countries. Journal of Comparative Economics 34(1), 1-23. 
Favero, C.A., M. Marcellino, and F. Neglia (2005) Principal components at work: The empirical analysis of monetary policy with large data sets. Journal of Applied Econometrics 20, 603-620.

Ganev, G., K. Molnar, K. Rybinski, and P. Wozniak (2002) Transmission Mechanism of Monetary Policy in Central and Eastern Europe. CASE report 52, Center for Social and Economic Research, Warsaw.

Gavin, W.T. and D.M. Kemme (2009) Using extraneous information to analyze the monetary policy in transition economies. Journal of International Money and Finance 28(5), 868-879.

Jarocinski, M. (2010) Responses to monetary policy shocks in the east and the west of Europe: A comparison. Journal of Applied Econometrics 25(5), 833-868.

Lütkepohl, H. (2005) New Introduction to Multiple Time Series Analysis. Berlin: Springer-Verlag.

Mihov, I. (2001) Monetary policy implementation and transmission in the European monetary union. Economic Policy 16(33), 369-406.

Mojon, B. and Peersman, G. (2001) A VAR Description of the Effects of Monetary Policy in the Individual Countries of the Euro Area. Working paper series 092, European Central Bank.

Peersman, G. and F. Smets (2001) The Monetary Transmission Mechanism in the Euro Area: More Evidence from VAR Analysis (MTN Conference Paper). Working paper series 091, European Central Bank.

Phillips, P.C.B. (1998) Impulse response and forecast error variance asymptotics in nonstationary VARs. Journal of Econometrics 83, 21-56.

Sims, C.A., J.H. Stock, and M.W. Watson (1990) Inference in linear time series models with some unit roots. Econometrica 58(1), 113-144.

Stock, J.H. and M.W. Watson (2002a) Forecasting using principal components from a large number of predictors. Journal of the American Statistical Association 97, 1167-1179.

Stock, J.H. and M.W. Watson (2002b) Macroeconomic forecasting using diffusion indexes. Journal of Business and Economic Statistics 20(2), 147-162.

Stock, J.H. and M.W. Watson (2005) Implications of Dynamic Factor Models for VAR Analysis. Working paper 11467, National Bureau of Economic Research.

\section{APPENDIX: VARIABLES AND DATA SOURCES}

The data consist of monthly data for the period 1995M01-2013M12. All series are obtained from the IMF-IFS statistics (via Datastream) and the precise Datastream mnemonics are available on request.

For the acceding country VARs we use data on the log of industrial production, the $\log$ of a consumer price index, the interest rate, and the exchange rate (local currency to ECU/Euro).

To extract the EMU factor time series, we use data from 11 EMU members (Austria, Belgium, Finland, France, Germany, Italy, Ireland, Luxembourg, the Netherlands, Portugal, and Spain). The variables are industrial output (IP), unemployment rate (UN), imports and exports (IMP and EXP), consumer and producer price index (CPI and PPI), short- and longterm interest rates (RS and RL), exchange rates (EXR), and share prices (SP). The same variables (except the long-term interest rates) have been used from the acceding countries to extract the acceding country factor time series. The transformation used before the factor analysis is given in Table 1 . 